\title{
ANÁLISE DO CONHECIMENTO TEÓRICO- METODOLÓGICO DA PRESERVAÇÃO DIGITAL SOB A ÓTICA DA OAIS, SAAI, ISO 14721 E NBR 15472
}

Analysis of theoretical-methodological knowledge of digital preservation from the perspective of OAIS, SAAI, ISO 14721 and NBR 15472

\section{Daniel Flores (1), Daiane Segabinazzi Pradebon (2), Graziella Cé (3)}

(1) UFSM, danielflores.arquivologia@gmail.com; (2) UFSM, daianepradebon@gmail.com; (3) UFCSPA, graziellace@gmail.com

\begin{abstract}
Resumo
Este artigo visa aprofundar o conhecimento teóricometodológico sobre o Open Archival Information System (OAIS) ou Sistema Aberto para Arquivamento de Informação (SAAI), a ISO 14721 e NBR 15472, sob a ótica da Arquivologia. Para isso, são abordados elementos da Resolução Conarq $n^{\circ}$ 39, de 29 de abril de 2014, conjuntamente ao modelo OAIS, definindo um conjunto mínimo de responsabilidades para um Arquivo ser chamado de Arquivo OAIS ou de Repositório Arquivístico Digital Confiável (RDC-Arq). O OAIS ou SAAI é um modelo conceitual para organização de sistemas e pessoas voltado a preservação e acesso de documentos em longo prazo, podendo abranger também outras áreas da Ciências da Informação, como a Biblioteconomia e a Museologia. Parece claro afirmar que na Arquivologia a utilização do OAIS é consenso para a manutenção de documentos digitais a longo prazo. Portanto, a sua ampliação pode servir para promover a interoperabilidade entre bibliotecas, arquivos, museus e demais instituições que trabalham com informação digital. Por outro lado, as instituições carecem de projetos teóricos e práticos de preservação digital, provavelmente pela falta de profissionais capacitados para atuar na área. Por fim, é preciso investir em formações curriculares voltados à preservação da informação digital para além dos ambientes de arquivo.
\end{abstract}

Palavras-chave: Arquivologia; OAIS; Informação; Preservação Digital

\section{Introducão}

É fato que a tecnologia digital está cada vez mais indispensável no cotidiano das pessoas, seja no trabalho ou nos assuntos profissionais. Os smartphones e/ou Iphones substituíram as máquinas fotográficas, na mesma perspectiva as fotos em suporte de papel foram substituídas pelas fotos digitais armazenadas em HDs e pendrives. Muitas empresas hoje trabalham apenas com processos nato digitais, híbridos, etc. Além disso, se poderia citar muitas outras mudanças que ocorreram com a evolução tecnológica.

Nesse ínterim, muitos documentos registrados em sistemas informacionais não estão mais disponíveis para consulta devido a obsolescência de hardwares,

\begin{abstract}
This article aims to deepen the theoretical-methodological knowledge about Open Archival Information System (OAIS) or open system for archiving information (SAAI), ISO 14721 and NBR 15472, under the optical of Archivist Science. For this, the elements of the resolution Conarq No. 39, of 29 April 2014, together with the model OAIS, defining a minimum set of responsibilities for a file to be called the OAIS file or the reliable Digital archival repository (RDCarch). The OAIS or SAAI is a conceptual model for organization of systems and people focused on preservation and access of long-term documents, and can also encompass other areas of Information Sciences, such as Librarianship and Museology. It seems clear to affirm that in Archivist Science the use of OAIS is consensus for maintaining digital documents in the long term. Therefore, its enlargement can serve to promote interoperability between libraries, archives, museums and other institutions working with digital information. On the other hand, the institutions lack theoretical and practical projects of digital preservation, probably by the lack of skilled professionals to act in the area. Finally, you need to invest in curricular formations that are focused on the preservation of digital information beyond the archive environments.
\end{abstract}

Keywords: Archival Science; OAIS; Information; Digital Preservation

softwares e formatos de arquivos. Além disso, muitos sistemas de informação não estão preparados para garantir a produção e a gestão arquivística desses documentos. Dentre eles, documentos de guarda permanente com valor informativo, testemunhal e que fazem alusão à história nacional e à pesquisa científica. Isso tudo, vinculada a carência de políticas, estratégias e planos capazes de garantir a preservação dos documentos digitais.

A este cenário, ainda, soma-se às novas demandas de trabalho as quais os arquivistas tradicionalmente não estão acostumados a enfrentar. Termos como metadados, software livre, repositório, migração, padronização de formato, que de fato torna a preservação digital uma atividade bastante complexa, devem começar a fazer parte do dia-a-dia dos 
profissionais responsáveis pela gestão documental nas instituições.

Em linhas gerais, a preservação digital caracteriza-se no desenvolvimento teórico e na aplicação de técnicas capazes de viabilizar a permanência, garantindo o acesso e a autenticidade dos objetos digitais. Nessa perspectiva, projetos e iniciativas com o objetivo de amenizar problemas e propor soluções a esses desafios são muito importantes.

Embora nota-se o aumento de pesquisas sobre a preservação digital no contexto mundial, a sua aplicabilidade ainda é uma incógnita na maioria das instituições brasileiras. Dessa forma, este artigo busca construir uma visão global sobre os modelos de aplicação existentes, a fim de apoiar iniciativas práticas de preservação digital nas organizações. Sendo assim, a temática de preservação digital será abordada no contexto teórico-metodológico, com ênfase no modelo de referência Open Archival Information System (OAIS), na ISO 14721 e NBR 15472. Também será aprofundada a temática dos ambientes de preservação e de produção.

\section{Descrição do modelo OAIS-SAAI}

$\mathrm{O}$ acesso à informação, o advento da Internet e a presença diária da tecnologia na vida das pessoas e das organizações modificou o cenário documental no mundo. E com essas modificações a preocupação com a preservação digital a longo prazo tornou-se temáticas de pesquisas devido a complexidade das questões envolvidas. Para Márdero Arellano (2008), o uso extensivo das tecnologias digitais e o registro de informações em soluções cada vez mais complexas passou a ser preocupação de todos aqueles profissionais que lidam com informações científicas em formato digital.

Em meados de 1990, o Consultative Comitee for Space Data Systems (CCSDS), em cooperação com a International Organization for Standardization (ISO), desenvolveu recomendações práticas para armazenamento em longo prazo de informações digitais produzidas por missões espaciais. Esse trabalho resultou na publicação da primeira versão do Reference Model for an Open Archival Information System (OAIS), em 1999. Após a sua revisão, pelo Comitê Consultivo, em 2002, evoluiu para o Padrão ISO 14721:2003. Embora tenha sido originalmente desenvolvido como recomendação para uso de agências espaciais, tornou-se um modelo de referência para muitas instituições em todo o mundo. No Brasil, por exemplo, houve uma adaptação com posterior publicação da norma ABNT NBR 15472:2007, sob o título Sistema Aberto de Arquivamento de Informação (SAAI).

A mais recente versão do OAIS, e, também da ISO 14721, de 2012, teve por objetivo aumentar a conscientização e a compreensão de conceitos relevantes para o arquivamento de objetos digitais. Esse modelo trouxe algumas mudanças substanciais e esclarecimentos em relação a determinados conceitos, dentre eles, o da autenticidade com a introdução da noção de propriedade da informação transformacional (CCSDS, 2012). O OAIS define um alto nível de modelo de referência para preservação de longo prazo de documentos digitais, e:

- fornece os conceitos necessários às organizações para serem participantes efetivas no processo de preservação;

- fornece uma estrutura, incluindo terminologia e conceitos, para descrever e comparar arquiteturas e operações existentes e futuras;

- fornece uma estrutura para descrever e comparar diferentes estratégias e técnicas de preservação a longo prazo;

- fornece uma base para comparar os modelos de dados de informações digitais preservados pelos Arquivos e para discutir como os modelos de dados e as informações subjacentes podem mudar ao longo do tempo;

- fornece uma estrutura que pode ser expandida para cobrir a preservação a longo prazo de informações que não estão em formato digital (por exemplo, mídia física e amostras físicas);

- amplia o consenso sobre os elementos e os processos de preservação e acesso a longo prazo; e

- orienta a identificação e produção de padrões relacionados ao OAIS. (CCSDS, 2012, p. 1, tradução nossa).

O OAIS é uma estrutura conceitual para um sistema arquivístico dedicado a preservar e manter o acesso a informações digitais a longo prazo. "Longo prazo" é suficientemente longo para se preocupar com os impactos de mudanças tecnológicas, podendo se estender indefinidamente (CCSDS, 2012). O modelo basicamente define um ambiente de preservação digital, por meio de um conjunto mínimo de responsabilidades, para um Arquivo ser chamado de Arquivo OAIS. No Brasil, um Arquivo OAIS é interpretado como um Repositório Arquivístico Digital Confiável (RDC-Arq), que será visto mais especificamente no capítulo 4 deste artigo.

O documento aborda uma série de funções de armazenamento, gerenciamento, acesso e disseminação de pacotes de informações para arquivo. Aborda também a migração de documentos digitais para novas mídias e formatos, os modelos de dados usados para representar a informação, o papel do software na preservação e a troca de informações digitais entre Arquivos. Está estruturado em seis seções. A Seção 1 trata dos aspectos gerais, como finalidade, alcance e aplicabilidade. A Seção 2 fornece uma visão de alto nível dos principais conceitos e os papéis envolvidos em um Arquivo OAIS. A Seção 3 descreve as responsabilidades equiparadas a um OAIS, define as 
responsabilidades obrigatórias e fornece material dos tipos de atividades que podem ser necessárias para cumprir essas responsabilidades. A Seção 4 ilustra o modelo necessário para uma compreensão detalhada de um Arquivo OAIS e explica uma série de áreas funcionais, além de identificar alguns serviços de alto nível nas interfaces. Já a Seção 5, fornece algumas perspectivas sobre a preservação através da migração digital e os problemas de preservação de serviços de acesso a informações digitais usando portabilidade de software e emulação de hardware. E, por fim, a Seção 6 é uma introdução às várias alternativas para fornecer serviços aumentados ou mais econômicos.

Em primeiro lugar é necessário entender o funcionamento de um Arquivo OAIS e suas interações. Isto é abordado mais especificamente nas segunda e quarta seções do modelo de referência. Desta forma, devido à complexidade do tema, apenas essas seções serão aprofundadas neste artigo.

$\mathrm{Na}$ Seção 2, são definidos os papéis das entidades do ambiente OAIS, sendo elas o produtor, o administrador e o consumidor. O produtor é o papel desempenhado por pessoas ou sistemas externos que fornecem a informação a ser preservada. Nesse caso, os produtores podem ser tantos os sistemas de produção de documentos digitais quanto os indivíduos que estão diretamente ligados a sua produção. O Administrador é o papel desempenhado por aqueles que definem a política em um nível mais amplo, como parte de uma organização. Como, por exemplo, a política de gestão e de preservação digital, que deve ser desenvolvida pelo arquivo com o apoio da alta administração a fim de ser a principal fonte de financiamento de um OAIS. No entanto, não está envolvida diretamente nas operações de arquivo do dia-a-dia. O consumidor é o papel desempenhado por pessoas que procuram encontrar informações de seu interesse, através de pedido de informações ou por plataformas que viabilizam o acesso aos documentos.

A Figura 1, ilustra este ambiente e também fornece uma visão detalhada dos fluxos específicos de informações entre as entidades citadas e as entidades funcionais do OAIS. Esse assunto é especificamente abordado na Seção 4 do OAIS.

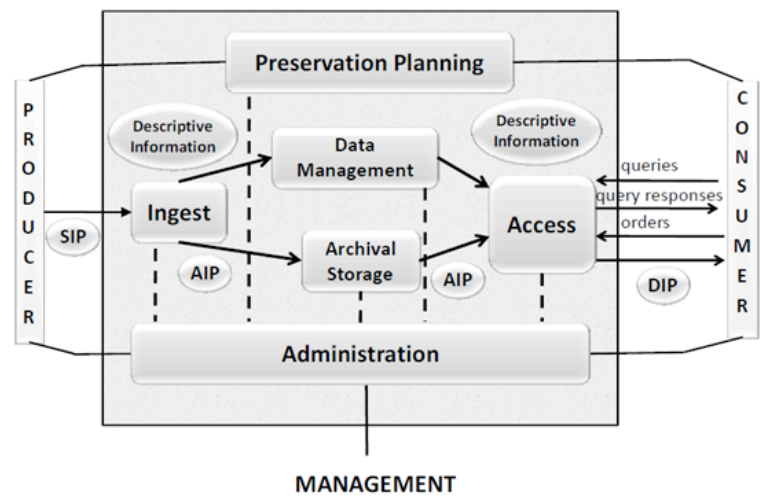

Figura 1. Modelo funcional do OAIS.

Fonte: (CCSDS, 2012).

No Arquivo OAIS, cada entidade funcional é responsável por determinados procedimentos. As principais entidades são: Ingestão, Administração, Área de Armazenamento, Gerenciamento de Dados, Acesso e Planejamento de Preservação. Ainda há outros serviços considerados como entidade funcional, porém, demanda uma análise mais aprofundada e minuciosa dos fluxos de dados dentro e entre as entidades de um ambiente OAIS. Nesse sentido, estão ilustrados, nas Figura 2 e 3, os principais fluxos do OAIS.

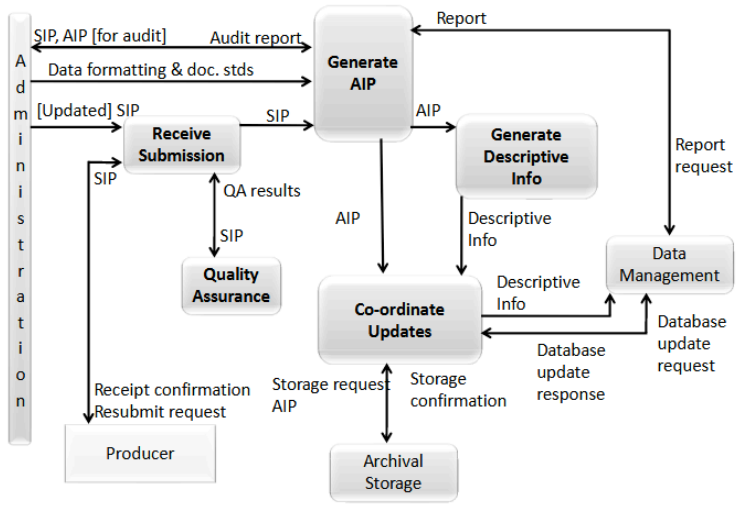

Figure 4-2: Functions of the Ingest Functional Entity

Figura 2. Entidade funcional Ingestão.

Fonte: (CCSDS, 2012).

A entidade funcional Ingestão engloba os serviços necessários para preparar os conteúdos de armazenamento e gerenciamento de dados dentro do Arquivo OAIS, através de Pacotes de Informação para Submissão (SIP). Os SIPs devem ser enviados pelo produtor, que fornece as evidências de autenticidade necessárias para a sua aceitação. Sendo que, o recebimento da submissão representa a transferência legal de custódia para o Arquivo responsável.

$\mathrm{Na}$ entidade funcional Administração são gerenciadas as "solicitação e negociação de acordos de submissão com Produtores, auditando submissões para garantir 
que atinjam aos padrões do Arquivo" (CCSDS, 2002, p. 2, tradução nossa). Nesta etapa, pode ser necessária a complementação de informações de representação para garantir que as informações de conteúdo sejam compreensíveis e acessíveis.

Após a obtenção de garantia de qualidade de SIPs, é gerado um Pacote de Informações de Arquivo (AIP), que atende a padrões de dados estabelecidos por uma política de arquivo, definida pela Administração: formato de arquivo, informações de representação, dentre outros. Por conseguinte, são extraídas Informações Descritivas dos AIPs. Isso inclui metadados para a busca e recuperação de AIPs (por exemplo, procedência, classificação, data, hora, localização), e também pode incluir miniaturas de imagens. Por fim, os AIPs são transferidos para a Área de Armazenamento e as Informações Descritivas para o Gerenciamento de Dados. Na entidade funcional Área de Armazenamento são executadas as funções necessárias para receber, armazenar e recuperar AIPs para acesso, além de efetuar medidas rotineiras de manutenção.

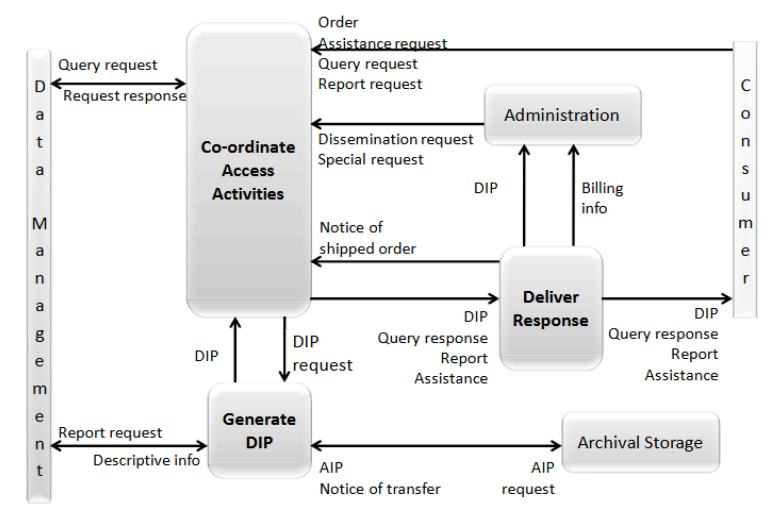

Figure 4-7: Functions of the Access Functional Entity

Figura 3. Entidade funcional Acesso.

Fonte: (CCSDS, 2012).

A entidade funcional Gerenciamento de Dados é responsável por manter a integridade das informações descritivas dos documentos no banco de dados e também por adicionar novas informações. Além disso, permite que os consumidores requisitem e recebam informações por meio dos Pacotes de Informações para Disseminação (DIP). O DIP é o "pacote de informação gerado a partir do AIP, entregue ao usuário do repositório na sequência de uma operação de pesquisa sobre o catálogo do repositório" (CCSDS, 2012, tradução nossa). Na entidade funcional Acesso são coordenados os pedidos de informações para execução de solicitações bem-sucedidas, gerando respostas (DIPs) e entregando-as aos Consumidores (CCSDS, 2012).
Por fim, a entidade funcional Planejamento de Preservação fornece serviços que permitem monitorar o ambiente do OAIS, formulando e executando as estratégias de preservação digital das informações armazenados, mesmo que o contexto tecnológico original se torne obsoleto.

Já existem algumas iniciativas importantes de desenvolvimento de softwares baseados no padrão exigido pelo modelo OAIS, como por exemplo, o "Repositório de Objectos Digitais Autênticos" (RODA), desenvolvido através do projeto "Memória e Gestão Documental na Administração Pública" da Direcção-Geral de Arquivos (DGARQ) da Universidade de Lisboa. E o Archivematica, software livre desenvolvido pela empresa canadense Artefactual Systems, tendo a colaboração da UNESCO, Arquivo Municipal da cidade de Vancouver - Canadá; da Biblioteca da Universidade de British Columbia Canadá; entre outros.

\section{0 ambiente de preservação}

$\mathrm{O}$ acesso à informação, o advento da Internet e a A preservação digital fundamenta-se no desenvolvimento e aplicação de técnicas capazes de viabilizar a permanência e garantir a perenidade dos documentos digitais. Por isso, projetos e iniciativas com o objetivo de propor soluções a esses desafios são muito importantes. O Open Archival Information System (OAIS), por exemplo, é um modelo conceitual o qual as instituições e desenvolvedores devem utilizar como padrão para sistemas voltados à preservação de documentos arquivísticos digitais.

No Brasil, o Conselho Nacional de Arquivos (CONARQ) aprovou, através da Resolução no 39, de 29 de abril de 2014, às Diretrizes para a implementação de Repositórios Digitais Confiáveis de Documentos Arquivísticos (RDC-Arq), redigida pela Câmara Técnica de Documentos Eletrônicos (CTDE). O objetivo é de orientar aos órgãos e entidades integrantes do Sistema Nacional de Arquivos (SINAR) quanto à preservação e acesso em longo de objetos digitais autênticos. Esta normativa foi atualizada pela Resolução $n^{\circ} 43$, de 04 de setembro de 2015, que altera a redação de RDC-Arq para Repositórios Arquivísticos Digitais Confiáveis.

Esta normativa considera os conceitos de "repositório digital", "repositório arquivístico digital" e "repositório digital confiável". O primeiro caracteriza-se como uma solução informatizada, formada por elementos de hardware, software e metadados, que gerencia e armazena materiais digitais embasado em procedimentos normativos e técnicos. O segundo inclui procedimentos arquivísticos relacionadas à gestão documental nas fases corrente, intermediária e permanente, descrição arquivística e preservação, com 
vistas a proteger as características de autenticidade e manter a relação orgânica entre os documentos.

Já um repositório digital confiável, além de manter autênticos os objetos digitais, de preservá-los e prover acesso a eles pelo tempo necessário, contém algumas atribuições e responsabilidades específicas, baseados em normas e padrões de referências nacionais e internacionais. Uma delas é a ISO 16363:2012, que aborda três critérios que os repositórios digitais confiáveis devem atender, são eles: "requisitos de infraestrutura organizacional", "requisitos de tecnologia, infraestrutura técnica e segurança" e "requisitos de gerenciamento do documento digital".

No âmbito da ISO 16363, os requisitos de "infraestrutura organizacional" buscam dar sustentação e compromisso organizacional com a preservação digital e abrangem o ambiente em que o repositório digital vai se estabelecer, como a gestão da instituição, a estrutura de pessoal, além de tratar dos problemas administrativos e financeiros. Pode incluir, por exemplo, a capacitação de pessoas responsáveis pela produção e manutenção de documentos digitais e o desenvolvimento de políticas alinhadas à missões institucionais.

Os requisitos de "tecnologia, infraestrutura técnica e segurança”, abordam infraestrutura de sistema, tecnologias apropriadas e segurança. Estes descrevem as melhores práticas das áreas de gestão de dados e segurança, porém não prescrevem hardware e software específicos para garantir a preservação de longo prazo. Os "requisitos para gerenciamento do documento no repositório digital" são baseados na ISO 14721:2003, que consiste na formação de pacotes de informação, de acordo com o modelo OAIS, para admissão de objetos digitais no repositório.

Bullock (1999 apud Márdero Arellano, 2004), baseando-se no OAIS identificou alguns elementos fundamentais para a preservação digital a longo prazo a citar: fixar os limites do objeto a ser preservado; preservar a presença física: preservar o conteúdo; preservar a apresentação; preservar a funcionalidade; preservar a autenticidade; localizar e rastrear o objeto digital ao longo do tempo; preservar a proveniência; preservar o contexto. Esse autor considera esses os requisitos mínimos, ou seja, ainda existem outros requisitos que devem ser considerados na manutenção dos documentos digitais a longo prazo.

O Archivematica, por exemplo, é um software livre de código aberto que integra um conjunto ferramentas que permite aos usuários processar documentos digitais e metadados de preservação, de acordo com o modelo funcional ISO-OAIS. O projeto é gerenciado pela empresa canadense Artefactual Systems, tendo a colaboração da UNESCO e de diversas outras instituições. O sistema ainda possibilita aos usuários gerenciar os micro-serviços de ingestão e preservação dos objetos digitais através de um painel de controle baseado em ambiente web. O Archivematica utiliza padrões de metadados reconhecidos, como PREMIS e Dublin Core, para gerar pacotes de informações para arquivo (AIPs) confiáveis, autênticos e interoperáveis para preservação no repositório.

Paralelamente a isso, a norma ISO 16919: 2014, estabelece requisitos para as entidades certificadoras de repositórios digitais confiáveis. O objetivo principal desta norma, é definir uma prática ao qual as organizações que avaliam a confiabilidade dos repositórios digitais usando a ISO 16363 devem basear as operações para fornecer uma certificação apropriada.

Nesse contexto, um repositório arquivístico digital confiável, de acordo com as diretrizes para implementação de RDC-Arq do Conarq, "deve ser capaz de atender aos procedimentos arquivísticos em suas diferentes fases e aos requisitos de um repositório digital confiável" (CTDE, 2015).

Distretti (2017), analista do Serviço Federal de Processamento de Dados (Serpro), ilustrou as quatro situações prováveis de repositórios na Figura 4. De acordo com ele, o RCD-Arq possui elementos dos demais ambientes e, ainda, deve garantir a preservação de todos os documentos arquivísticos digitais de temporalidade permanente de uma instituição. A Serpro é considerada a maior empresa pública de tecnologia de informação do Brasil e desenvolveu sistemas como RAIS, Renavam, Siafi, Receitanet, dentre outros.

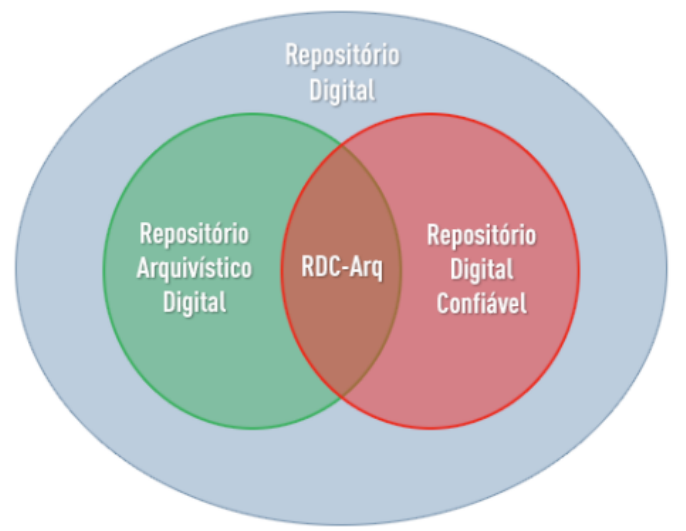

Figura 4. Repositórios.

Fonte: (Distretti, 2017).

Diante do exposto, os repositórios digitais para serem arquivísticos precisam cumprir os requisitos da Arquivologia incluindo o arranjo, a descrição e o acesso, a fim de assegurar a manutenção da autenticidade, da relação orgânica e do vínculo arquivístico dos documentos, em concordância assim com a Resolução Conarq $n^{0}$ 43/2015. Portanto, plataformas que são amplamente utilizadas em outras áreas da ciência da informação, como DSpace, Fedora, dentre outros, podem vir a ser repositórios arquivísticos 
digitais confiáveis, tendo que para isso contemplar os requisitos dispostos nesta resolução.

A utilização de um RCD-Arq, segundo a Resolução 43 do CONARQ (2015, p. 18), deve incluir aspectos de segurança como:

- análise sistemática de dados, sistemas, pessoas e instalação física;

- adoção de procedimentos de controle para tratar adequadamente as necessidades de segurança;

- delineamento de papéis, responsabilidades e autorizações relativas à implementação de mudanças no sistema; e

- plano de prevenção de desastres e de reparação, que inclua, ao menos, um backup, offsite, de tudo o que é mantido no repositório (documentos, metadados, trilhas de auditoria etc.), inclusive do próprio plano de reparação.

Para a segurança de um repositório é recomendado abranger a blindagem do ambiente, conforme ilustrado na Figura 1. Para isso, é de suma importância o controle de acesso, backups e ambientes offsites (fora da Internet), inseridos em planos de preservação com alto nível de especialidades de segurança da informação. Prevenindo, dessa forma, problemas com perdas de informação. Como visto anteriormente, os requisitos para um repositório digital confiável, expostos na ISO 16363, se observados permitem o acesso confiável e seguro dos dados, informações e documentos digitais.

A preservação e, especificamente, a utilização do RCD-Arq, pode evitar muitos problemas de segurança da informação. Como o caso, divulgado pelo jornal $\mathrm{O}$ globo $^{1}$, do dia 20 de outubro de 2016, da invasão dos sites de tribunais estaduais de justiça do Brasil, que tiveram de desligar seus servidores, devido a invasão de hackers. Outro fato ocorreu no dia 12 de maio de 2017, no Reino Unido: de acordo com o jornal El Pais ${ }^{2}$, um ciberataque paralisou 16 hospitais e exigiu dinheiro para libertar as informações sequestradas. Casos como esses não apenas põem em risco a segurança de informações e documentos, mas também propiciam a violação à intimidade e à vida privada das pessoas.

O Tribunal de Contas do Estado do Amazonas (TCEAM) teve problemas na execução um script no SQL dos sistemas e-Contas e Spede (Sistema de Processos e Documentos Eletrônicos), o que resultou na exclusão de cerca de 16,5 mil processos, conforme reportagem do dia 06 de outubro de 2017 do site Terra ${ }^{3}$. Da mesma forma, poderiam ser enumerados outros tantos casos de perdas semelhantes. Porém, essa situação já demonstra que os ambientes digitais não estão seguros e, tampouco, preparados para garantir a preservação e acesso a longo prazo de documentos.

De acordo com dados oficiais do Observatório de Documentos Digitais ${ }^{4}$, algumas instituições de ensino superior no Brasil alegam desconhecimento de metodologias na produção e preservação de documentos digitais. E a maior parte delas afirmaram não adotar repositórios confiáveis para a preservação de seus documentos. Em uma pesquisa desenvolvida por esse observatório nas Instituições Federais de Ensino Superior (IFES) constatou-se que 57\% produzem documentos digitais, $91 \%$ não tem plano de preservação digital e $89 \%$ não adotam um RDC-Arq. Nesse sentido, observa-se que as IFES não estão produzindo ferramentas voltadas à preservação de longo prazo dos documentos arquivísticos digitais, fragilizando-os, assim como também não garantindo a presunção de autenticidade dos mesmos.

Nesse sentido os arquivos governamentais possuem uma importância fundamental, pois para Ambacher (2008), os arquivos do governo possuem um papel de liderança, assim como os profissionais da informação tem a obrigação de liderar e apontar caminhos na implantação dos repositórios digitais. Esses arquivos podem ser exemplos para outras organizações e, conforme atendam aos requisitos das listas de verificação de auditoria, auxiliar no processo de implantação dos repositórios em outras instituições, fornecendo inclusive equipe para atuar como auditores. Ainda, podem desenvolver estudos de caso ilustrativos para orientar a implantação de outros repositórios, promovendo o processo de auditoria com órgãos políticos, conselhos de regulamentação, doadores potenciais e usuários.

O trabalho e iniciativas em conjunto de cursos relacionados a Ciência da Informação e instituições relacionado ao conhecimento teórico e prático da preservação digital pode ser uma alternativa para a construção de metodologias que visem trabalhar com as especificidades dos documentos digitais.

Nesse sentido, a especificidades de documentos de arquivos exigem que as instituições trabalhem com o ciclo vital dos documentos. O ciclo de vida atualmente é a base teórica metodológica das formações acadêmicas no Brasil. Porém, a forma de abordagem do ciclo vital tem sido constantemente criticada por modelos baseados no pós-custodialismo ${ }^{5}$ e do Records Continu mm $^{6}$, em que os Arquivistas passam a atuar mais ativamente na gestão documental desde a produção do documento. Esses modelos buscam trabalhar com foco na cadeia de custódia e preservação desde a produção dos documentos digitais.

3.1 A cadeia de preservação e de custódia

A nova perspectiva de atuação desde a produção documental e os modelos internacionais, como o OAIS e o projeto InterPARES ${ }^{7}$, apontaram novos conceitos adaptados a realidade dos documentos digitais como cadeia de custódia e cadeia de preservação. 
Voutssas (2011), dispõe que o modelo da cadeia de preservação estabelece que os arquivos digitais sejam cuidadosamente administrados ao longo de sua existência para que sejam acessíveis e legíveis, mantendo a sua forma, conteúdo e relações intactas. Dessa forma, atestando confiabilidade aos documentos de arquivo. Para esse autor todas as atividades da administração do documento estão interrelacionadas como uma cadeia e interdependentes entre si. Se algum processo e/ou atividades não são realizadas sobre um documento de arquivo, sua confiança, ou seja, sua fidedignidade e autenticidade ou exatidão se tornam questionáveis.

A efetividade da preservação digital existe a integridade e a confiabilidade dos arquivos e esses atributos só podem ser obtidos a partir da produção e perpassa todo o ciclo de vida dos documentos. Assim sendo, a cadeia de preservação contempla os procedimentos de produção, avaliação, tramitação, destinação, preservação dos documentos a longo prazo. Além disso, a cadeia de preservação deve estar embasada pela implementação de legislações, normas, metodologias e requisitos, que podem ser definidos antes mesmo do desenvolvimento de sistemas informatizados até sua preservação a longo prazo em Repositórios Arquivísticos Digitais Confiáveis.

Nesse sentido, o Conselho Nacional de Arquivos publicou a Resolução $n^{\circ}$ 32, de 17 de maio de 2010, que estabelece um modelo de requisitos para um Sistema Informatizado de Gestão Arquivística de Documentos (SIGAD). Esse sistema deve ser utilizado nas fases corrente e intermediária, oferecendo uma solução completa de gestão de documentos, desde a produção até a destinação final dos documentos (eliminação ou guarda permanente), constituindo-se em um ambiente de gestão confiável. Portanto, o modelo OAIS deve ser pensado no estudo da implementação do SIGAD, pois garante o contínuo da manutenção, preservação e difusão dos documentos arquivísticos digitais a longo prazo.

Nesse viés, destaca-se a relação direta da perspectiva de responsabilidade e posse dos documentos com a abordagem de cadeia de custódia. A custódia refere-se à responsabilidade legal e física dos documentos, independentemente de vínculo de propriedade, já que a partir da destinação para a guarda permanente, a responsabilidade pela preservação dos documentos passa dos produtores para a instância de guarda (Conselho Nacional de Arquivos, 2015). Portanto, a cadeia de custódia acompanha o ciclo de vida dos documentos, desde as fases corrente e intermediária até a guarda permanente, e determina responsabilidades na aplicação e utilização de funções arquivísticas.

De acordo com Flores (2015), a manutenção da cadeia ininterrupta de custódia é fundamental para a presunção de autenticidade, preservação e acesso dos documentos arquivísticos digitais. Através dela, é possível manter os documentos sob procedimentos regulares e que podem ser comprovados.

A cadeia de custódia e preservação são hoje base para o desenvolvimento de metodologias, projetos e normas de gestão e preservação digital de documentos arquivísticos digitais. A Orientação Técnica $n^{\circ} 3$ da Câmara Técnica de Documentos Eletrônicos do Conarq, por exemplo, dispõe sobre os cenários de uso de RCD-Arqs (Resolução Conarq n. ${ }^{\circ} 43$ ) em conjunto com SIGADs. Além do mais, a cadeia de custódia possui relação direta com a Lei dos Arquivos n. ${ }^{\circ} 8159$ de 08 de janeiro de 1991, Lei de Acesso à Informação n. ${ }^{\circ} 12.527$ de 18 de novembro de 2011, assim como projeto InterPARES (Flores, 2015).

Por fim, no universo digital, as especificidades inerentes aos documentos de arquivo necessitam de novas abordagens teóricas-metodológicas para garantir a preservação e acesso a longo prazo de documentos autênticos e confiáveis. Portanto, a produção de documentos arquivísticos digitais, tendo em vista a cadeia de preservação e custódia, devem ser contemplados em políticas informacionais e consideradas também nos aspectos de governança institucional, assim como nas legislações concernentes aos documentos arquivísticos.

\section{Conclusões}

À ótica das referências citadas neste artigo, a preservação digital está intrinsecamente ligada ao acesso futuro de diversos elementos que compõem os documentos digitais. Além disso, depende da instituição de políticas, da adequação de sistemas e da formação de equipe com responsabilidade e competência de preservar e dar acesso aos documentos arquivísticos digitais. Portanto, não se limita apenas a acompanhar a evolução tecnológica, mas a manter a integridade e a acessibilidade dos objetos digitais em longo prazo.

O êxito da preservação digital resulta de um acompanhamento ininterrupto dos documentos digitais, aliada a medidas que podem ser planejadas antes mesmo da produção dos documentos digitais, através de políticas e normas institucionais. Estas políticas devem orientar os diversos segmentos e serviços atuantes e voltados para a proteção da informação digital, especificamente as área de arquivos, bibliotecas e museus, em parceria com a área de tecnologia da informação.

Embora o modelo OAIS tenha sido publicado há mais de 10 anos e já existam diversas estratégias de preservação digital que podem ser utilizadas conjuntamente, no Brasil a prática nessa área apenas começou a engatinhar. A resolução do Conarq $n^{\circ} 43$, de 04 de setembro de 2015, teve seu embasamento no OAIS ou SAAI, visando produzir, manter e preservar 
os documentos digitais, com especificidades e conceitos voltados a Arquivologia, para definir um RDC-Arq. Tanto o modelo OAIS quanto a resolução Conarq $n^{\circ} 43$, devem se expandir atingindo profissionais de arquivos, museus, bibliotecas e tecnologia da informação. Essa expansão para além dos ambientes de arquivo é de suma importância para difundir as políticas e estratégias de preservação digital, pois os registros digitais para que sejam acessíveis ao longo do tempo devem ser criados, mantidos e preservados como autênticos

Em termos de formação curricular, nos cursos Ciência da Informação faltam disciplinas e práticas voltadas à produção, manutenção e preservação das informações digitais. A inserção de programas disciplinares com essas temáticas, possibilita a formação de profissionais capacitados para atuarem na preservação digital nas instituições.

Os profissionais da tecnologia da informação e os gestores de organizações não podem mais deixar seus acervos digitais em bases temporárias e pensar que de fato irão preservá-los por prazo indeterminado. É preciso que sejam participantes ativos nos esforços de preservação a longo prazo, e, juntamente com profissionais da Ciência da Informação, compreendam os problemas e tomem as medidas adequadas. Dessa forma, o primeiro passo, tanto para as instituições quanto para os pesquisadores e profissionais responsáveis pelos acervos digitais, é tomar consciência e se atualizar quanto às práticas e referenciais teóricos e, assim, estar sempre um passo à frente da obsolescência tecnológica.

\section{Notas}

(1) O Globo (2016). Hackers invadem sistema do STJ e divulgam dados de servidores. // Jornal O Globo. Rio de Janeiro, $20 \quad$ out. 2016. https://oglobo.globo.com/brasil/hackers-invademsistema-do-stj-divulgam-dados-de-servidores-20325466 (25-11-2017).

(2) El País (2017). Ciberataque paralisa 16 hospitais do Reino Unido. // Jornal El País. Londres, 12 mai. 2017. https://brasil.elpais.com/brasil/2017/05/12 internacional/1494602389_458942.html (25-11-2017).

(3) Terra (2017). Funcionário do TCE-AM executa script errado no SQL e apaga 16,5 mil processos. // Terra. Canaltech, 62 out. 2017. $<$ https://www.terra.com.br/noticias/tecnologia/canaltech/f uncionario-do-tce-am-executa-script-errado-no-sql-eapaga-165-mil-

processos, 18725b33381ae4c1a836258082b17985hztswaz 3.html > (23-11-2017)

(4) O Portal Observatório de Documentos Digitais é uma iniciativa do Grupo de Pesquisa CNPq/UFSM Ged/A Gestão Eletrônica de Documentos Arquivísticos, coordenado pelo Professor e Doutor Daniel Flores. Portal Observatório de Documentos Digitais, Google Sites. // Disponível
$<$ https://sites.google.com/view/observatoriodocumentosdi gitais/p\%C3\%A1 gina-inicial?authuser=0 $>$ (24-11-2017).

(5) A arquivística pós-custodial está pautada na ótica do pensamento pós-moderno, em que os princípios e pressupostos dos arquivos estão inseridos em um momento histórico, social e político específico. Nesse âmbito, se questiona o considerado convencional, natural e lógico até o momento.

(6) O Records Continuum vem se tornando uma alternativa ao ciclo vital dos documentos, por meio de uma visão mais holísticas das atividades arquivísticas, quebrando a linearidade do modelo convencional. Nessa abordagem, os arquivistas trabalham na produção documental e não existe divisão entre arquivo corrente e permanente. Esse modelo é resultado da evolução da Arquivologia australiana, considerando os aspectos teóricos e práticos de sua construção.

(7) O InterPARES (International Research on Permanent Authentic Records in Electronic Systems) é um projeto coordenado pela professora Luciana Duranti da University of British Columbia (UBC) desde 1994, e, atualmente, possui colaboração de diversos países. O Projeto busca estabelecer normas para a criação de documentos eletrônicos de confiança e manter a sua autenticidade durante a sua vida ativa e semi-ativa, tendo como base teórica a integração dos princípios e conceitos da diplomática e da arquivística. Projeto InterPARES. // Disponível em: http://www.interpares.org (24-11-2017).

\section{Referências}

Ambacher, Bruce (2008). Government archives and the digital repository audit checklist. // JoDI - Journal of Digital Information 63-73. $<$ https://journals.tdl.org/jodi/index.php/jodi/article/viewFile/190/ 171>. (16-07-2017)

Brasil. Ministério da Justiça. Arquivo Nacional. Conselho Nacional de Arquivos (2015). Diretrizes para a implementação de repositórios arquivísticos digitais confiáveis - RDC-Arq. Rio de Janeiro, 2015.

Consultive Committee for Space Data Systems (CCSDS) (2012) Reference Model for an Open Archival Information System (OAIS). // CCSDS 650.0-M-2. Magenta Book, Recommended Practice, Issue 2012. $<$ https://public.ccsds.org/Pubs/650x0m2.pdf $>(11-2017)$.

Distretti, Henrique Alvares (2017). Repositório arquivístico digital confiável - $\quad$ RDC-Arq, 2017. $<\mathrm{http} / /$ intra.serpro.gov.br/tema/artigos-opinioes/repositorioarquivistico-digital-confiavel-2013-rdc-arq $>(20$-11- 2017).

Flores, Daniel (2015). A Arquivologia e os Arquivos em Ambientes Digitais. Brasília - D, 2015. (Material elaborado para a Palestra IBICT - Instituto Brasileiro de Informação em Ciência e Tecnologia, de 01 a 03 de dezembro de 2015 - 97 slides, color, Padrão Slides Google Drive/Docs 4x3). $<$ http://documentosdigitais.blogspot.com $>$ (01-11-2017).

Márdero Arellano, M. A (2008). Critérios para a preservação digital da informação científica. 2008. $354 \mathrm{f}$. // Tese (Doutorado em Ciência da Informação) Universidade de Brasília, Departamento de Ciência da Informação, 2008. http://www.repositorio.unb.br/bitstream/10482/1518/1/2008_Mi guelAngelMarderoArellano.pdf (17-10-2017).

Márdero Arellano, M. A (2004). Preservação de documentos digitais // Ciência da Informação 33: 2 (maio/ago 2004) 15-27. 
Márquez, Juan Voutssás (2011). La cadena de preservación en archivos digitales. // Alicia Barnard (ed.). Archivos electrónicos: Textos y contextos. Mexico Red Nacional de Archivos de Educación Superior y Archivo Histórico de la Universidad Nacional Autónoma de Puebla, 143-167.

Copyright: (C) 2017. Flores, Pradebon e Cé. This is an open-access article distributed under the terms of the Creative Commons CC Attribution-ShareAlike (CC BY-SA), which permits use, distribution, and reproduction in any medium, under the identical terms, and provided the original author and source are credited.

Flores, Daniel; Pradebon, Daiane Segabinazzi; Cé, Graziella. Análise do conhecimento teórico-metodológico da preservação digital sob a ótica da OAIS, SAAI, ISO 14721 e NBR 15472 // Brazilian Journal of Information Science: Research Trends. 11:4 (2017) 72-80. ISSN 1981-1640. 